\title{
Marginal Cord Insertion
}

National Cancer Institute

\section{Source}

National Cancer Institute. Marginal Cord Insertion. NCI Thesaurus. Code C117348.

The location of the umbilical cord insertion at the disc edge. 